\title{
Stereoelectroencephalography in Pediatric Epilepsy Surgery
}

\author{
Samuel B. Tomlinson, B.A., ${ }^{1,2}$ Vivek P. Buch, M.D., ${ }^{3}$ Dallas Armstrong, M.D., ${ }^{4}$ Benjamin C. Kennedy, M.D. \\ Division of Neurosurgery, Children's Hospital of Philadelphia, Philadelphia, PA, USA \\ School of Medicine and Dentistry, ${ }^{2}$ University of Rochester Medical Center, Rochester, NY, USA \\ Department of Neurosurgery, ${ }^{3}$ Hospital of the University of Pennsylvania, Philadelphia, PA, USA \\ Division of Child Neurology, ${ }^{4}$ Children's Hospital of Philadelphia, Philadelphia, PA, USA
}

\begin{abstract}
Stereoelectroencephalography (SEEG) is an invasive technique used during the surgical management of medically refractory epilepsy. The utility of SEEG rests in its ability to survey the three-dimensional organization of the epileptogenic zone as well as nearby eloquent cortices. Once concentrated to specialized centers in Europe and Canada, the SEEG methodology has gained worldwide popularity due to its favorable morbidity profile, superior coverage of deep structures, and ability to perform multilobar explorations without the need for craniotomy. This rapid shift in practice represents both a challenge and an opportunity for pediatric neurosurgeons familiar with the subdural grid approach. The purpose of this review is to discuss the indications, technique, and safety of long-term SEEG monitoring in children. In addition to reviewing the conceptual and technical points of the diagnostic evaluation, attention will also be given to SEEG-based interventions (e.g., radiofrequency thermo-coagulation).
\end{abstract}

Key Words : Stereoelectroencephalography · Invasive monitoring $\cdot$ Epilepsy surgery $\cdot$ Pediatrics.

\section{INTRODUCTION}

Resective epilepsy surgery is the most effective treatment for controlling seizures and improving quality of life among children with medically refractory epilepsy $y^{5,32,34,79,83,95)}$. The critical step towards achieving favorable surgical outcomes is the accurate delineation of the epileptogenic zone (EZ), or the "minimum amount of cortex that must be resected to produce seizure freedom"65). Conceptually, the EZ constitutes a network of structures involved in the generation and propagation of seizures ${ }^{3)}$. The goal of epilepsy surgery is to disrupt this net- work through resection, disconnection, targeted ablation, neurostimulation, or some combination thereof. In some cases, non-invasive evaluation is sufficient to determine the surgical plan, but children frequently require invasive exploration with intracranial electrodes to achieve high-resolution delineation of the EZ and nearby eloquent cortices ${ }^{333}$.

Stereoelectroencephalography (SEEG) is an invasive technique used to localize the EZ prior to epilepsy surgery. Pioneered in the 1950s by the French neurosurgeon Jean Talairach and neurologist Jean Bancaud ${ }^{80,81}$, the SEEG methodology involves stereotactic implantation of multi-contact intracerebral electrodes

- Received : January 8, 2019 •Revised : February 1, 2019 •Accepted : February 5, 2019

- Address for reprints : Benjamin C. Kennedy, M.D.

Division of Neurosurgery, Children's Hospital of Philadelphia, 3401 Civic Center Blvd, Philadelphia, PA 19104, USA

Tel : +1-215-590-2780, Fax : +1-215-590-4809, E-mail : kennedybc@email.chop.edu

This is an Open Access article distributed under the terms of the Creative Commons Attribution Non-Commercial License (http://creativecommons.org/licenses/by-nc/4.0) which permits unrestricted non-commercial use, distribution, and reproduction in any medium, provided the original work is properly cited. 
for three-dimensional sampling of the EZ. The goal of the SEEG exploration is to establish a spatiotemporal correlation between electrical events in the brain and the patient's clinical semiology (i.e., the 'anatomo-electro-clinical' correlation) ${ }^{46}$. Once concentrated to specialized European centers, SEEG has achieved worldwide usage as a safe and less invasive alternative to monitoring with subdural grid (SDG) electrodes.

This widespread shift in practice has ushered in a new era of SEEG literature, with many studies focused on the pediatric population $^{1,20,42,44,52,59)}$. The purpose of this review is to discuss the indications, goals, and technical aspects of invasive SEEG exploration in children. Special attention is given to literature assessing the safety and efficacy of long-term SEEG monitoring. Finally, we briefly discuss the expanding role of SEEG in minimally-invasive epilepsy surgery.

\section{INDICATIONS}

\section{Non-invasive evaluation}

All epilepsy surgery candidates undergo a routine series of non-invasive tests to formulate an initial anatomo-electroclinical hypothesis. According to the International League Against Epilepsy (ILAE) Subcommission for Pediatric Epilepsy Surgery ${ }^{26)}$, mandatory components of the non-invasive evaluation include : 1) clinical assessment of epilepsy history, neurological examination, and semiology; 2) interictal scalp EEG recordings (video-EEG capturing ictal events strongly recommended); and 3) structural magnetic resonance imaging (MRI) with epilepsy protocols.

Complementary modalities providing structural, functional, and metabolic data include neuropsychiatric evaluation, computed tomography (CT), magnetoencephalography (MEG), functional MRI, transcranial magnetic stimulation, ictal single photon emission computed tomography (SPECT), positron emission tomography, and other specialized exams (e.g., Wada test). The contributions of these ancillary methods to the overall surgical plan are often difficult to define ${ }^{17,75)}$. In a practice survey of 20 pediatric centers ${ }^{50)}$, approximately $2 / 3$ children who proceeded to resection required non-invasive evaluation only, commonly in the setting of an MRI lesion with concordant semiology and scalp electrophysiology $y^{36}$.

\section{Invasive monitoring with SEEG}

Invasive monitoring is the standard approach for localizing the $\mathrm{EZ}$ when non-invasive methods are inconclusive ${ }^{60)}$. The two main invasive techniques for long-term monitoring are subdural grids and SEEG. Both methodologies have distinct strengths and weaknesses (Table 1). Subdural electrodes are placed directly on the cortical surface via craniotomy and provide excellent coverage of superficial cortex. Mapping the onset and spread of seizures across the cortical surface is made intuitive by the contiguous arrangement of electrodes, and the high-density coverage of key eloquent cortices (e.g., motor cortex) allows for extensive functional testing with cortical stimulation $^{72}$. SEEG is the preferred modality when the noninvasive evaluation necessitates further evaluation of medial or deep structures (Table 1). This includes any medial cortex, depths of sulci, the insula, and mesial temporal lobe. Percutaneous electrode insertion has a favorable morbidity and tolerability profile relative to craniotomy for SDG placement (see "SAFETY, ACCURACY, AND EFFICACY"). This improved safety and tolerability is particularly evident when widespread or bi-hemispheric coverage is desired. Revising the initial implantation strategy by removing and adding SEEG electrodes is also considerably safer than repositioning SDGs through reopening or expanding the original craniotomy ${ }^{58}$. Finally, SEEG is frequently able to localize the EZ when subdural monitoring has failed ${ }^{91}$, thereby availing otherwise inoperable patients of the well-known benefits of epilepsy surgery ${ }^{34,94)}$.

No consensus guidelines exist for adjudicating between SEEG, grids, or a combination of surface and depth electrodes

Table 1. Comparison of the subdural grid and SEEG methodologies for invasive monitoring

\begin{tabular}{|c|c|c|}
\hline Goal & Subdural & SEEG \\
\hline $\begin{array}{l}\text { Sampling from superficial } \\
\text { cortex }\end{array}$ & Superior & Inferior \\
\hline $\begin{array}{l}\text { Interpreting spatial electrode } \\
\text { relationships }\end{array}$ & Easy (2-D arrays) & $\begin{array}{l}\text { Difficult (3-D } \\
\text { configuration) }\end{array}$ \\
\hline Mapping functional circuits & Inferior & Superior \\
\hline $\begin{array}{l}\text { Multi-lobar or bilateral } \\
\text { exploration }\end{array}$ & Inferior & Superior \\
\hline Morbidity and tolerability & $\begin{array}{l}\text { Inferior } \\
\text { (craniotomy) }\end{array}$ & $\begin{array}{l}\text { Superior } \\
\text { (percutaneous) }\end{array}$ \\
\hline $\begin{array}{l}\text { Ability to revise the initial } \\
\text { implantation strategy }\end{array}$ & Inferior & Superior \\
\hline
\end{tabular}


when planning the invasive strategy. Beyond the general rationale for invasive monitoring, the following indications favor SEEG over subdural recording ${ }^{20,44,54,55)}: 1$ ) hypothesized involvement of deep structures; 2) widespread, multi-focal, or unclear localization of hypothesized ictal onset zone; 3) previous unsuccessful investigation with subdural electrodes; 4) absence of a lesion on MRI imaging; and 5) proposed minimally-invasive treatment strategy (see "THERAPEUTIC APPLICATIONS”).

\section{TECHNICAL PROCEDURES}

\section{Preparation}

The technique for performing SEEG monitoring in children has been described elsewhere ${ }^{2,20,42)}$. Briefly, the methodology begins with non-invasive evaluation and the formulation of an initial anatomo-electro-clinical hypothesis. All patients requiring invasive exploration are discussed at multi-disciplinary conference, where an implantation strategy is devised targeting the presumed seizure onset zones, the propagation territory, relevant eloquent regions, and any structural or functional lesions (e.g., as seen on MEG or SPECT). Sentinel electrodes probing remote cortices may be included to "ruleout" areas of lingering suspicion. Additional electrodes may be added to help define safe resection limits. The goal of exhaustive coverage must be weighed against the small but additive risk conferred by each intracerebral electrode. Strategies vary among institutions, but larger implantations are often 13-15 electrodes ${ }^{17)}$. Routine neuroimaging is performed to facilitate trajectory planning and neuro-navigation. At our institution, the imaging protocol consists of high-resolution (3 Tesla) gadolinium-enhanced MRI and thin-slice volumetric CT with contrast. Other groups variably use CT angiography or conventional angiography as well. Regardless of the stereotactic approach, the basic goals are to plan structural targets and avoid major blood vessels with the electrodes. Once desired targets are identified, electrode trajectories can be planned in computer-assisted fashion ${ }^{76)}$ to maximize the number of desired structures monitored with as few electrodes as possible.

\section{Electrode placement}

After the implantation strategy is determined, the neurosurgical team will meet with the patient and family to discuss the rationale for invasive monitoring, procedural details, monitoring plans, and risks/benefits before scheduling a surgical date. Intraoperatively, the patient is administered general anesthesia via endotracheal tube. Electrode placement can be performed using frame-based, frameless stereotactic, or robotassisted methods ${ }^{92)}$. At our institution, the Robotic Stereotactic Assistant (Zimmer Biomet, Warsaw, IN, USA) system is used for robot-assisted electrode placement. As is the case for any stereotactic procedure, accurate registration of pre-operative imaging to the patient's surface anatomy is essential. Registration procedures vary based on the implantation method but must be scrutinized carefully prior to proceeding. After registration is accepted and equipment is calibrated, the planned trajectories are mapped to ensure the robot or surgeon will be able to align each electrode trajectory without colliding with the patient, head mount, or other electrodes. Electrode implantation is comprised of a sequence of steps (Fig. 1) : 1) alignment and verification of trajectory; 2) stab incision with scalpel blade; 3) drilling of small (2-3 mm) burr hole; 4) durotomy with insulated probe and cautery; 5) placement of anchor bolt into burr hole; 6) measurement of electrode length required to achieve target depth (i.e., distance from top of anchor bolt to target); 7) calculating the error between planned electrode length and actual length. High errors require careful re-assessment before the electrode is passed intracranially; 8) placement of electrode through anchor bolt to target depth; 9) securing electrode to anchor bolt; and 10) proceeding to the next trajectory.

A unique label is assigned to each electrode (e.g., 'Electrode A'), which is carefully documented for later reference. At some institutions, electrodes may be temporarily plugged in to confirm that recording quality is appropriate before exiting the operating room. Post-operative imaging is performed using CT and/or MRI for localization of electrode positions and to confirm the absence of procedure-related complications.

\section{Monitoring}

The interpretation of SEEG recordings shares many core principles with the reading of subdural grid recordings. In both modalities, electrographic findings of interest mainly include seizures (onset and propagation) and interictal paroxysms (e.g., spikes, sharps, high-frequency oscillations, etc.), and the duration of monitoring depends on the time needed to capture sufficient electrographic evidence to support or refute the pre-implantation hypothesis. Issues specific to SEEG 


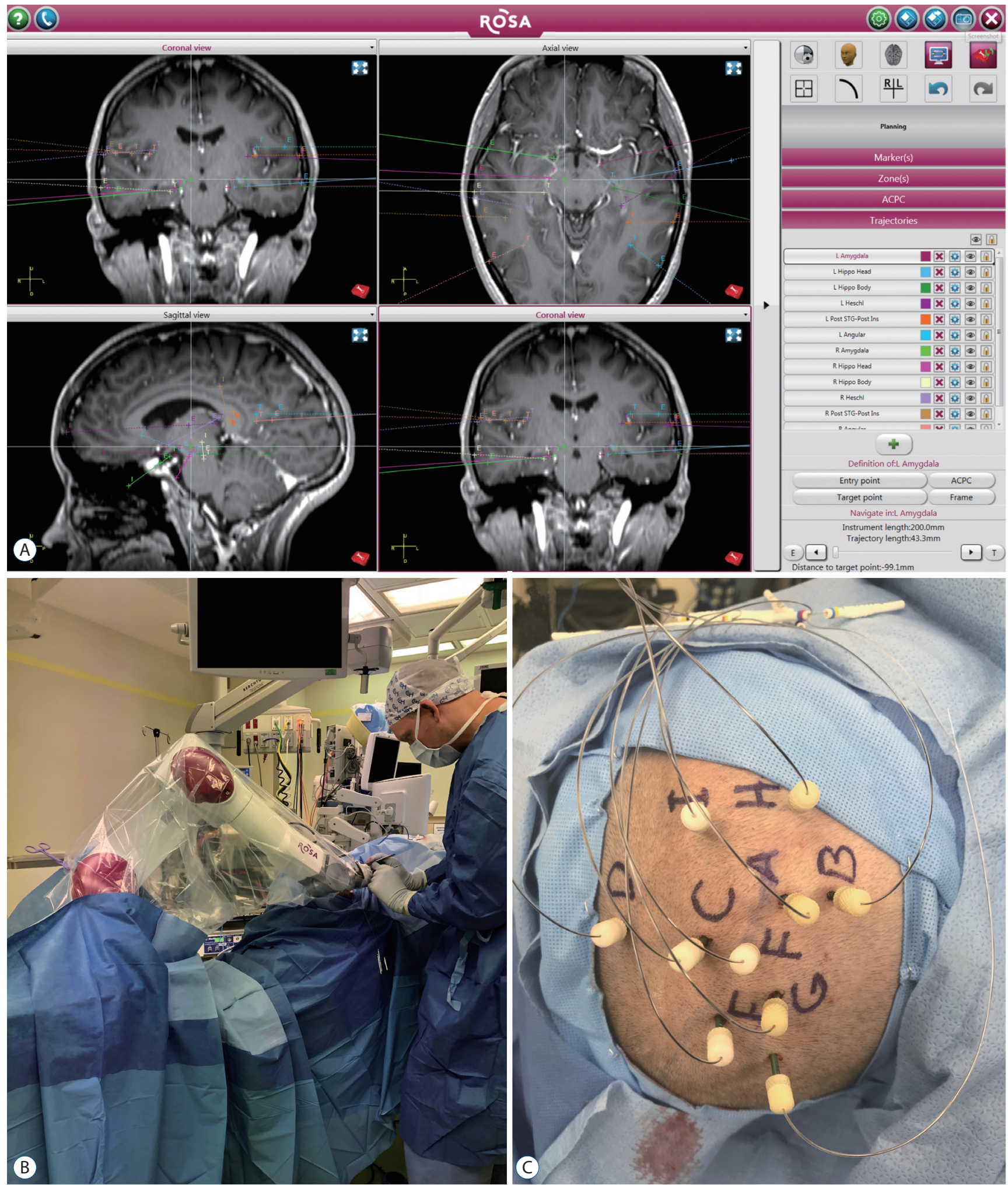

Fig. 1. Stereoelectroencephalography (SEEG) procedure. A : The Robotic Stereotactic Assistant planning software (Zimmer Biomet, Warsaw, IN, USA), demonstrating a bitemporal SEEG plan in a patient for whom bitemporal subdural strips failed to adequately localize seizure onset. B: The robot arm moves into position for each electrode, and instruments are placed through an instrument holder on the robot arm to each stereotactic target. C : Intraoperative photograph of secured electrodes after implantation. 
interpretation include the need to consider complex three-dimensional relationships between contacts and electrodes ${ }^{4)}$, the novelty of recording from white matter ${ }^{10)}$, and the particular artifact patterns present in SEEG recordings ${ }^{577}$. Unlike grids, each SEEG electrode typically samples the neocortex, white matter, and deep structures (e.g., amygdala, hippocampus, insula, cingulate) via contacts at varying depths. On bipolar projections, white matter recordings appear relatively isoelectric, which can serve as a landmark to distinguish between recordings of the neocortex and deeper structures. Common artifacts present in SEEG recordings include muscle artifact in superficial contacts (especially in electrodes that pierce the temporalis muscle), $60-\mathrm{Hz}$ line noise, and infrequent electrode breakage. Lastly, it bears repeating that intracranial monitoring via intracerebral electrodes constitutes only a portion of the broader SEEG methodology $y^{17)}$, which calls for a complete assimilation of the invasive and non-invasive findings when finalizing the treatment plan.

\section{SAFETY, ACCURACY, AND EFFICACY}

\section{Safety}

SEEG exploration is a relatively safe procedure. The majority of institutional studies examining outcomes from pediatric SEEG exploration reported either no procedure-related com-

Table 2. Selective summary of institutional series reporting outcomes from pediatric SEEG exploration

\begin{tabular}{|c|c|c|c|c|c|c|}
\hline Study & Specific population & $\begin{array}{l}\text { Children/ } \\
\text { SEEGs }\end{array}$ & $\begin{array}{l}\text { Electrodes }(N) / \\
(\mu \pm \sigma \text { per case) }\end{array}$ & $\begin{array}{l}\text { Resective } \\
\text { surgery (\%) }\end{array}$ & Engel I (\%) & $\begin{array}{c}\text { SEEG-related } \\
\text { complications (\%) }\end{array}$ \\
\hline Abel et al..$^{2)}(2018)$ & $\begin{array}{l}\text { Robot-assisted vs. } \\
\text { Talairach frame }\end{array}$ & $35 / 38$ & $529(13.9 \pm N R)$ & 68.6 & $41.7^{*}$ & $\begin{array}{l}\text { Asymptomatic ICH (13.2) } \\
\text { Symptomatic ICH (5.3) }\end{array}$ \\
\hline Cossu et al.."1) (2005) & - & $35 / 37$ & $426(11.5 \pm 2.6)$ & 100 & $60.0^{*}$ & Electrode breakage (2.7) \\
\hline Cossu et al. ${ }^{25)}(2012)$ & $<4 \mathrm{y} / \mathrm{o}$ & $15 / 16$ & $192(12.0 \pm 2.6)$ & 86.7 & $60.0^{*}$ & None $(0)^{\dagger}$ \\
\hline Dorfmüller et al. ${ }^{31)}$ (2014) & $<5 y / 0+F C D$ & $19 / 19$ & $\mathrm{NR}(11.6 \pm \mathrm{NR})$ & 100 & $84.2^{*}$ & None (0) \\
\hline Dylgjeri et al..$^{35)}(2014)$ & Insulo-opercular & $10 / 10$ & $115(11.5 \pm 1.8)$ & 100 & $70.0^{\ddagger}$ & None (0) \\
\hline Francione et al..$^{37)}$ (2003) & FCD & $6 / 6$ & $69(11.5 \pm 1.0)$ & 100 & $66.7^{\S}$ & None (0) \\
\hline Freri et al. ${ }^{38)}(2017)$ & Perisylvian/insular & $8 / 8$ & NR (13.3 $\pm N R)$ & 100 & $50.0^{\S}$ & None (0) \\
\hline Goldstein et al. ${ }^{39)}$ (2018) & - & $25 / 30$ & $342(11.4 \pm 3.4)$ & 72.0 & $53.3^{\ddagger}$ & $\begin{array}{l}\text { SDH (3.3\%) } \\
\text { Scalp infection (6.7) }\end{array}$ \\
\hline Gonzalez-Martinez et al. ${ }^{43)}$ (2014) & $\begin{array}{l}\text { "Difficult-to-localize" } \\
\text { seizures }\end{array}$ & $30 / 30$ & $402(13.4 \pm 1.0)$ & 60.0 & $55.6 \% *$ & $\begin{array}{l}\text { Small/asymptomatic ICH } \\
\text { (3.3) }\end{array}$ \\
\hline González-Martínez et al. ${ }^{41)}$ (2016) & Robot-assisted & $14 / 14$ & NR & 100 & $64.3^{\ddagger}$ & None $(0)$ \\
\hline Ho et al. ${ }^{53)}(2018)$ & Robot-assisted & $20 / 20$ & $222(11.1 \pm 2.4)$ & 95.0 & $50.0^{\ddagger}$ & None (0) \\
\hline Liava et al. ${ }^{63)}$ (2012) & Extra-temporal, $<12$ y/o & $34 / N R$ & NR & 97.1 & $66.7^{\|}$ & None (0) \\
\hline Liava et al. ${ }^{64)}(2014)$ & Posterior cortex & $24 / 24$ & NR & 100 & $75.0^{\S}$ & $N R$ \\
\hline McGonigal et al. ${ }^{69)}(2007)$ & $\begin{array}{l}\text { Non-lesional }(n=12) ; \\
\text { lesional }(n=9)\end{array}$ & $21 / 21$ & NR & 71.4 & $53.3^{\ddagger}$ & NR \\
\hline Munari et al. ${ }^{74)}$ (1999) & $<16 y / 0$ & $27 / N R$ & NR & 100 & $56.2^{\|}$ & NR \\
\hline Taussig et al. ${ }^{88)}$ (2012) & $2-3 y / 0$ & $6 / 6$ & NR & 83.3 & $80.0^{\ddagger}$ & None (0) \\
\hline Taussig et al. ${ }^{87)}$ (2014) & $\begin{array}{l}<5 \text { y/o }(n=21) \\
\geq 5 \text { y/o }(n=44)\end{array}$ & $65 / 71$ & NR (11.5 $\pm N R)$ & 78.5 & $66.7^{*}$ & None (0) \\
\hline Taussig et al. ${ }^{89)}$ (2016) & Engel Class la & $48 / 51$ & 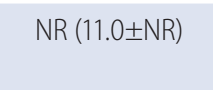 & \multicolumn{2}{|c|}{$\begin{array}{l}\text { Cohort of surgical patients } \\
\text { with Engel la outcome* }\end{array}$} & $\begin{array}{l}\text { Small/asymptomatic ICH } \\
\text { (2.0) }\end{array}$ \\
\hline
\end{tabular}

*Minimum reported follow-up duration : 12 months. ${ }^{\dagger}$ One patient died on post-implant Day \#1 due to severe hyponatremia and cerebral edema of uncertain cause. ${ }^{\ddagger}$ Minimum reported follow-up duration : <12 months. ${ }^{5}$ Minimum reported follow-up duration : 24 months. "Minimum reported follow-up duration : 18 months. SEEG : stereoelectroencephalography, NR : not reported, ICH : intracranial hemorrhage, y/o : years old, FCD : focal cortical dysplasia, SDH : subdural hemorrhage 
plications, or infrequent minor complications (Table 2). The most common SEEG-related complications are electrode breakage, superficial infection, and vascular disruption causing minor intracranial hemorrhage (ICH). Cossu et al. ${ }^{21)}$ reviewed 37 pediatric SEEG cases and identified one electrode breakage requiring surgical removal across 426 electrodes implanted ( $0.2 \%$ breakages/electrode). Abel et al. $\left.{ }^{2}\right)$ identified four children with asymptomatic ICH, one case of transient paresthesia associated with subdural hematoma, and another with headache associated with a minor electrode-tract ICH among 38 procedures. Goldstein et al. ${ }^{39)}$ reviewed 30 SEEG explorations, finding one instance of electrode deflection resulting in asymptomatic extra-axial hemorrhage, and two cases of superficial scalp infection at the electrode entry site. These findings from pediatric series align with the more extensive literature involving adult or mixed cohorts ${ }^{9,12,16,40,49,68,86)}$, with a meta-analysis of SEEG outcomes from 2624 patients reporting a pooled prevalence of $1.0 \%$ for hemorrhagic complications and $0.8 \%$ for infectious complications ${ }^{73)}$. Previous studies demonstrate that SEEG monitoring can be performed safely in very young children (including infants and toddlers) ${ }^{25,31,87,88)}$ though some authors suggest a minimum skull thickness of 2 $\mathrm{mm}$ for safe placement of anchoring bolts ${ }^{55,70)}$. Finally, mortality associated with SEEG monitoring is extremely rare. In a meta-analysis of over 2500 SEEG explorations, mostly in adults, only five fatalities were reported $(0.2 \%)$ : two attributed to $\mathrm{ICH}$, two associated with complications from ventriculography, and one related to massive cerebral edema ${ }^{73)}$. In children, only a few peri-procedural fatalities have been report$\operatorname{ed}^{12,25,29)}$.

\section{Comparison to subdural grids}

Exploration with SEEG is safer and less invasive than SDG monitoring. Institutional series consistently demonstrate higher rates of hemorrhage, infection, and cerebral edema associated with SDGs ${ }^{56,77,85,97)}$. In a large pediatric series, Blauwblomme et al. ${ }^{6}$ reviewed 95 SDG investigations, finding that $29.8 \%$ of patients suffered a complication prolonging their hospital stay, $17.9 \%$ required unplanned reoperation, $16.8 \%$ developed subdural hemorrhage, and 14.7\% developed a wound infection. Yang et al. ${ }^{96)}$ performed an institutional study comparing outcomes from SDG $(n=52)$ and SEEG $(n=48)$, observing higher rates of ICH and surgical site infection among SDG patients. In a meta-analysis comparing SDG and SEEG, Sacino et al. ${ }^{84)}$ reviewed 23 papers featuring 974 children (SDG, 697; SEEG, 277), finding that SDG cases had a higher pooled-prevalence of CSF leak, infection, and ICH, as well as a lower overall seizure-freedom rate (SDG, 52.1\% vs. SEEG, 66.5\%).

\section{Accuracy}

Accurate electrode placement is critical for sampling the desired targets and minimizing complications. Placement accuracy is typically measured in terms of entry point (EP) and target point (TP) localization errors. Comprehensive discussion of SEEG placement accuracy using frame-based, frameless, and robot-assisted techniques is available elsewhere ${ }^{12,52)}$. A recent meta-analysis ${ }^{92)}$ found that the combined accuracy of frame-based systems (EP error, $1.43 \mathrm{~mm}$; 95\% confidence interval $[\mathrm{CI}], 1.35-1.51$; TP error, 1.93; 95\% CI, 1.05-2.81) compared favorably to frameless systems (EP error, 2.45; 95\% CI, 0.39-4.51; TP error, 2.89; 95\% CI, 2.34-3.44). However, localization errors $<2 \mathrm{~mm}$ have been reported using frameless and robot-assisted techniques in both pediatric and adult populations $^{11,12,28,41)}$.

\section{Efficacy}

Assessing the efficacy of SEEG is complicated. Most studies report the percentage of cases in which SEEG was "successful" or "useful" in localizing the EZ, but this definition lacks consistency across centers. The percentage of patients offered surgical resection after SEEG exploration is another flawed metric, given that SEEG findings can both rule-in or rule-out resection candidates. Additionally, post-operative seizurefreedom rates should not be confused with SEEG efficacy, as complete removal of the EZ may not be feasible even when it is well-localized (e.g., overlap with eloquent cortex).

Compared to adult patients, children with medically-refractory epilepsy (MRE) have a higher incidence of extra-temporal, non-lesional, cryptogenic, and syndromic epilepsies. SEEG may add value in these complex scenarios. In a study of extra-temporal epilepsy ${ }^{63)}, 34 / 53$ children (64.2\%) underwent SEEG investigation, and $66.7 \%$ of SEEG patients who underwent resection were seizure-free (Engel Class I) after 12 months. McGonigal et al. ${ }^{69)}$ reviewed a large cohort of MRIlesional and non-lesional patients undergoing SEEG exploration. In the full cohort (80 adults, 20 children), "successful" EZ localization was achieved in $96 \%$ of cases (55/57 lesional, 
41/43 non-lesional). Among 15 children who underwent resection, 4/8 children with non-lesional epilepsy and 4/7 children with lesional epilepsy were seizure-free after $\geq 6$ months. Gonzalez-Martinez et al. ${ }^{43)}$ reported 30 children with "difficult-to-localize" MRE, including 66\% with non-lesional, equivocal, or bilateral MRI findings. SEEG localized the EZ in $26 / 30$ cases $(86.7 \%)$, and $55.6 \%$ of children offered resection were seizure-free after 12 months. SEEG has also shown utility in specific MRE populations, including children with insular epilepsy $^{35)}$, periventricular nodular heterotopia ${ }^{90)}$, and polymicrogyria $^{67)}$.

\section{THERAPEUTIC APPLICATIONS}

In addition to diagnostic exploration, SEEG electrodes can be used to perform stereotactic ablation as a form of minimally-invasive epilepsy surgery. SEEG-guided radiofrequency thermocoagulation (RF-TC) is a technique used to produce focal areas of thermal injury and coagulative necrosis by delivering current through neighboring electrodes. RF-TC can be performed using the same electrodes implanted for passive recording, affording access to many lesion targets without the risk of additional electrode or laser fiber passages. Early work by Guénot and colleagues ${ }^{48)}$ established the safety and feasibility of RF-TC in a series of 20 patients with MRE, and in the years since, RF-TC has shown potential as a palliative option for a limited range of epilepsy-related indications ${ }^{7,8,13,15,19,22,24,71,90,93,98)}$. At present, the literature reporting outcomes of RF-TC in children ${ }^{14,23,30,47)}$ suggests a marginal role of RF-TC in pediatric MRE management, and is potentially useful as palliative therapy when the patient is not a candidate for resective surgery.

Laser ablation with MR-guided laser interstitial thermal therapy (MR-g-LITT) is another minimally-invasive technique in which a fiber-optic laser applicator is stereotactically inserted, and ablation is performed while acquiring real-time thermal MRI sequences ${ }^{27,45,61,62)}$. At some centers, SEEG electrodes are used to identify ablation targets ${ }^{82)}$. Favorable outcomes from SEEG followed by MR-g-LITT for children with MRE have been described ${ }^{18)}$, although one study reported a relatively high rate of transient functional deficits (7/24 procedures, $29.2 \%)^{78)}$. Similar to RF-TC, the precise role of MR-gLITT in pediatric MRE treatment remains undefined.

Finally, SEEG may be used to determine the optimal targets for the electrodes of responsive neurostimulation systems ${ }^{66)}$, which are designed to arrest seizures through closed-loop stimulation $^{51)}$. This is typically employed as a treatment strategy when seizure onset arises from eloquent areas.

\section{CONCLUSION}

Epilepsy surgery is an important treatment option for children with MRE. Invasive monitoring with subdural grids or SEEG electrodes is indicated when the non-invasive evaluation fails to conclusively localize the EZ. Extensive outcomes research involving pediatric and adult patients shows that SEEG exploration is very safe. As a diagnostic method, SEEG is particularly valuable when the anatomo-electro-clinical hypothesis predicts the involvement of deep structures, bilateral networks, or after unsuccessful investigation with subdural electrodes. Therapeutically, SEEG may be used to guide ablative therapies via RF-TC or MR-g-LITT. Continued adoption by epilepsy centers worldwide promises future innovation and an expanded role of SEEG in the surgical management of pediatric epilepsy.

\section{CONFLICTS OF INTEREST}

No potential conflict of interest relevant to this article was reported.

\section{INFORMED CONSENT}

This type of study does not require informed consent.

\section{References}

1. Abel TJ, Losito E, Ibrahim GM, Asano E, Rutka JT : Multimodal localization and surgery for epileptic spasms of focal origin: a review. Neurosurg Focus 45 : E4, 2018

2. Abel TJ, Varela Osorio R, Amorim-Leite R, Mathieu F, Kahane P, Minotti $L$, et al. : Frameless robot-assisted stereoelectroencephalography in children: technical aspects and comparison with Talairach frame technique. J Neurosurg Pediatr 22 : 37-46, 2018

3. Bartolomei F, Lagarde S, Wendling F, McGonigal A, Jirsa V, Guye M, et 
al. : Defining epileptogenic networks: contribution of SEEG and signal analysis. Epilepsia 58 : 1131-1147, 2017

4. Bartolomei F, Nica A, Valenti-Hirsch MP, Adam C, Denuelle M : Interpretation of SEEG recordings. Neurophysiol Clin 48 : 53-57, 2018

5. Bittar RG, Rosenfeld JV, Klug GL, Hopkins IJ, Harvey AS : Resective surgery in infants and young children with intractable epilepsy. J Clin Neurosci 9 : 142-146, 2002

6. Blauwblomme T, Ternier J, Romero C, Pier KS, D'Argenzio L, Pressler R, et al. : Adverse events occurring during invasive electroencephalogram recordings in children. Neurosurgery 69(2 Suppl Operative) : 169175; discussion ons175, 2011

7. Bourdillon P, Cucherat M, Isnard J, Ostrowsky-Coste K, Catenoix H, Guénot $M$, et al. : Stereo-electroencephalography-guided radiofrequency thermocoagulation in patients with focal epilepsy: a systematic review and meta-analysis. Epilepsia 59 : 2296-2304, 2018

8. Bourdillon P, Isnard J, Catenoix H, Montavont A, Rheims S, Ryvlin P, et al. : Stereo electroencephalography-guided radiofrequency thermocoagulation (SEEG-guided RF-TC) in drug-resistant focal epilepsy: results from a 10-year experience. Epilepsia 58 : 85-93, 2017

9. Bourdillon $P$, Ryvlin $P$, Isnard J, Montavont $A$, Catenoix $H$, Mauguière $F$, et al. : Stereotactic electroencephalography is a safe procedure, including for insular implantations. World Neurosurg 99 : 353-361, 2017

10. Bulacio JC, Chauvel P, McGonigal A : Stereoelectroencephalography: interpretation. J Clin Neurophysiol 33 : 503-510, 2016

11. Candela-Cantó S, Aparicio J, López JM, Baños-Carrasco P, RamírezCamacho A, Climent A, et al. : Frameless robot-assisted stereoelectroencephalography for refractory epilepsy in pediatric patients: accuracy, usefulness, and technical issues. Acta Neurochir (Wien) 160 : 24892500, 2018

12. Cardinale F, Cossu M, Castana L, Casaceli G, Schiariti MP, Miserocchi A, et al. : Stereoelectroencephalography: surgical methodology, safety, and stereotactic application accuracy in 500 procedures. Neurosurgery 72 : 353-366; discussion 366, 2013

13. Catenoix $H$, Bourdillon $P$, Guénot $M$, Isnard $J$ : The combination of stereo-EEG and radiofrequency ablation. Epilepsy Res 142 : 117-120, 2018

14. Catenoix $H$, Mauguière $F$, Guénot $M$, Ryvlin $P$, Bissery $A$, Sindou $M$, et al. : SEEG-guided thermocoagulations: a palliative treatment of nonoperable partial epilepsies. Neurology 71 : 1719-1726, 2008

15. Catenoix $H$, Mauguière $F$, Montavont $A$, Ryvlin $P$, Guénot $M$, Isnard J : Seizures outcome after stereoelectroencephalography-guided thermocoagulations in malformations of cortical development poorly accessible to surgical resection. Neurosurgery 77 : 9-14; discussion 14-15, 2015

16. Chassoux F, Devaux B, Landré E, Turak B, Nataf F, Varlet $P$, et al. : Stereoelectroencephalography in focal cortical dysplasia: a 3D approach to delineating the dysplastic cortex. Brain 123 (Pt 8) : 1733-1751, 2000

17. Chassoux F, Navarro V, Catenoix H, Valton L, Vignal JP : Planning and management of SEEG. Neurophysiol Clin $48: 25-37,2018$

18. Cobourn K, Fayed I, Keating RF, Oluigbo CO : Early outcomes of stereoelectroencephalography followed by MR-guided laser interstitial thermal therapy: a paradigm for minimally invasive epilepsy surgery. Neurosurg
Focus 45 : E8, 2018

19. Cossu M, Cardinale F, Casaceli G, Castana L, Consales A, D'Orio P, et al. : Stereo-EEG-guided radiofrequency thermocoagulations. Epilepsia 58 Suppl $1: 66-72,2017$

20. Cossu M, Cardinale F, Castana L, Nobili L, Sartori I, Lo Russo G : StereoEEG in children. Childs Nerv Syst 22 : 766-778, 2006

21. Cossu M, Cardinale F, Colombo N, Mai R, Nobili L, Sartori I, et al. : Stereoelectroencephalography in the presurgical evaluation of children with drug-resistant focal epilepsy. J Neurosurg 103(4 Suppl) : 333-343, 2005

22. Cossu M, Fuschillo D, Cardinale F, Castana L, Francione S, Nobili L, et al. : Stereo-EEG-guided radio-frequency thermocoagulations of epileptogenic grey-matter nodular heterotopy. J Neurol Neurosurg Psychiatry 85 : 611-617, 2014

23. Cossu M, Fuschillo D, Casaceli G, Pelliccia V, Castana L, Mai R, et al. : Stereoelectroencephalography-guided radiofrequency thermocoagulation in the epileptogenic zone: a retrospective study on 89 cases. J Neurosurg 123 : 1358-1367, 2015

24. Cossu M, Mirandola L, Tassi L : RF-ablation in periventricular heterotopia-related epilepsy. Epilepsy Res 142 : 121-125, 2018

25. Cossu M, Schiariti M, Francione S, Fuschillo D, Gozzo F, Nobili L, et al. : Stereoelectroencephalography in the presurgical evaluation of focal epilepsy in infancy and early childhood. J Neurosurg Pediatr 9 : 290300,2012

26. Cross JH, Jayakar P, Nordli D, Delalande O, Duchowny M, Wieser HG, et al. : Proposed criteria for referral and evaluation of children for epilepsy surgery: recommendations of the subcommission for pediatric epilepsy surgery. Epilepsia 47 : 952-959, 2006

27. Curry DJ, Gowda A, McNichols RJ, Wilfong AA : MR-guided stereotactic laser ablation of epileptogenic foci in children. Epilepsy Behav 24 : 408-414, 2012

28. De Benedictis A, Trezza A, Carai A, Genovese E, Procaccini E, Messina R, et al. : Robot-assisted procedures in pediatric neurosurgery. Neurosurg Focus 42 : E7, 2017

29. Derrey S, Lebas A, Parain D, Baray MG, Marguet C, Freger $P$, et al. : Delayed intracranial hematoma following stereoelectroencephalography for intractable epilepsy: case report. J Neurosurg Pediatr 10 : 525-528, 2012

30. Dimova P, de Palma L, Job-Chapron AS, Minotti L, Hoffmann D, Kahane $P$ : Radiofrequency thermocoagulation of the seizure-onset zone during stereoelectroencephalography. Epilepsia 58 : 381-392, 2017

31. Dorfmüller G, Ferrand-Sorbets S, Fohlen M, Bulteau C, Archambaud F, Delalande 0 , et al. : Outcome of surgery in children with focal cortical dysplasia younger than 5 years explored by stereo-electroencephalography. Childs Nerv Syst 30 : 1875-1883, 2014

32. Duchowny M, Jayakar P, Resnick T, Harvey AS, Alvarez L, Dean P, et al. : Epilepsy surgery in the first three years of life. Epilepsia 39 : 737-743, 1998

33. Ducis K, Guan J, Karsy M, Bollo RJ : Preoperative evaluation and surgical decision-making in pediatric epilepsy surgery. Transl Pediatr 5 : 169179,2016 
34. Dwivedi R, Ramanujam B, Chandra PS, Sapra S, Gulati S, Kalaivani M, et al. : Surgery for drug-resistant epilepsy in children. N Engl J Med 377 : 1639-1647, 2017

35. Dylgjeri S, Taussig D, Chipaux M, Lebas A, Fohlen M, Bulteau C, et al. : Insular and insulo-opercular epilepsy in childhood: an SEEG study. Seizure 23 : 300-308, 2014

36. Englot DJ : A modern epilepsy surgery treatment algorithm: incorporating traditional and emerging technologies. Epilepsy Behav 80 : 6874, 2018

37. Francione S, Vigliano P, Tassi L, Cardinale F, Mai R, Lo Russo G, et al. : Surgery for drug resistant partial epilepsy in children with focal cortical dysplasia: anatomical-clinical correlations and neurophysiological data in 10 patients. J Neurol Neurosurg Psychiatry 74 : 1493-1501, 2003

38. Freri E, Matricardi S, Gozzo F, Cossu M, Granata T, Tassi L : Perisylvian, including insular, childhood epilepsy: presurgical workup and surgical outcome. Epilepsia 58 : 1360-1369, 2017

39. Goldstein $\mathrm{HE}$, Youngerman BE, Shao B, Akman Cl, Mandel AM, McBrian DK, et al. : Safety and efficacy of stereoelectroencephalography in pediatric focal epilepsy: a single-center experience. J Neurosurg Pediatr 22 : 444-452, 2018

40. Gonzalez-Martinez J, Bulacio J, Alexopoulos A, Jehi L, Bingaman W, Najm I : Stereoelectroencephalography in the "difficult to localize" refractory focal epilepsy: early experience from a North American epilepsy center. Epilepsia 54 : 323-330, 2013

41. González-Martínez J, Bulacio J, Thompson S, Gale J, Smithason S, Najm I, et al. : Technique, results, and complications related to robot-assisted stereoelectroencephalography. Neurosurgery 78 : 169-180, 2016

42. Gonzalez-Martinez J, Lachhwani D : Stereoelectroencephalography in children with cortical dysplasia: technique and results. Childs Nerv Syst 30 : 1853-1857, 2014

43. Gonzalez-Martinez J, Mullin J, Bulacio J, Gupta A, Enatsu R, Najm I, et al. : Stereoelectroencephalography in children and adolescents with difficult-to-localize refractory focal epilepsy. Neurosurgery 75 : 258268; discussion 267-268, 2014

44. Gonzalez-Martinez J, Najm IM : Indications and selection criteria for invasive monitoring in children with cortical dysplasia. Childs Nerv Syst 30 : 1823-1829, 2014

45. Gonzalez-Martinez J, Vadera S, Mullin J, Enatsu R, Alexopoulos AV, Patwardhan $\mathrm{R}$, et al. : Robot-assisted stereotactic laser ablation in medically intractable epilepsy: operative technique. Neurosurgery 10 Suppl 2 : 167-172; discussion 172-173, 2014

46. Gonzalez-Martinez JA : The stereo-electroencephalography: the epileptogenic zone. J Clin Neurophysiol 33 : 522-529, 2016

47. Guénot $M$, Isnard J, Catenoix $H$, Mauguière $F$, Sindou $M$ : SEEG-guided RF-thermocoagulation of epileptic foci: a therapeutic alternative for drug-resistant non-operable partial epilepsies. Adv Tech Stand Neurosurg $36: 61-78,2011$

48. Guénot $M$, Isnard J, Ryvlin $P$, Fischer $C$, Mauguière $F$, Sindou $M$ : SEEGguided RF thermocoagulation of epileptic foci: feasibility, safety, and preliminary results. Epilepsia 45 : 1368-1374, 2004

49. Guenot M, Isnard J, Ryvlin P, Fischer C, Ostrowsky K, Mauguiere F, et al. :
Neurophysiological monitoring for epilepsy surgery: the Talairach SEEG method. Stereoelectroencephalography. Indications, results, complications and therapeutic applications in a series of 100 consecutive cases. Stereotact Funct Neurosurg 77 : 29-32, 2001

50. Harvey AS, Cross JH, Shinnar S, Mathern GW, ILAE Pediatric Epilepsy Surgery Survey Taskforce : defining the spectrum of international practice in pediatric epilepsy surgery patients. Epilepsia 49 : 146-155, 2008

51. Heck CN, King-Stephens D, Massey AD, Nair DR, Jobst BC, Barkley GL, et al. : Two-year seizure reduction in adults with medically intractable partial onset epilepsy treated with responsive neurostimulation: final results of the RNS system pivotal trial. Epilepsia 55 : 432-441, 2014

52. Ho AL, Feng AY, Kim LH, Pendharkar AV, Sussman ES, Halpern $C H$, et al. : Stereoelectroencephalography in children: a review. Neurosurg Focus $45: E 7,2018$

53. Ho AL, Muftuoglu Y, Pendharkar AV, Sussman ES, Porter BE, Halpern $\mathrm{CH}$, et al. : Robot-guided pediatric stereoelectroencephalography: single-institution experience. J Neurosurg Pediatr 22 : 1-8, 2018

54. lida $\mathrm{K}$, Otsubo $\mathrm{H}$ : Stereoelectroencephalography: indication and efficacy. Neurol Med Chir (Tokyo) 57 : 375-385, 2017

55. Isnard J, Taussig D, Bartolomei F, Bourdillon P, Catenoix H, Chassoux F, et al. : French guidelines on stereoelectroencephalography (SEEG). Neurophysiol Clin 48 : 5-13, 2018

56. Johnston JM Jr, Mangano FT, Ojemann JG, Park TS, Trevathan E, Smyth MD : Complications of invasive subdural electrode monitoring at St. Louis Children's Hospital, 1994-2005. J Neurosurg 105(5 Suppl) : 343-347, 2006

57. Kahane P, Dubeau F : Intracerebral depth electrodes electroencephalography (stereoencephalography), ed 4. Philadelphia : Wolters Kluwer Health, 2014, pp393-441

58. Kalamangalam GP, Tandon N : Stereo-EEG implantation strategy. J Clin Neurophysiol 33 : 483-489, 2016

59. Karsy M, Guan J, Ducis K, Bollo RJ : Emerging surgical therapies in the treatment of pediatric epilepsy. Transl Pediatr 5 : 67-78, 2016

60. Kovac S, Vakharia VN, Scott C, Diehl B : Invasive epilepsy surgery evaluation. Seizure 44 : 125-136, 2017

61. LaRiviere MJ, Gross RE : Stereotactic laser ablation for medically intractable epilepsy: the next generation of minimally invasive epilepsy surgery. Front Surg 3 : 64, eCollection 2016

62. Lewis EC, Weil AG, Duchowny M, Bhatia S, Ragheb J, Miller I : MR-guided laser interstitial thermal therapy for pediatric drug-resistant lesional epilepsy. Epilepsia 56 : 1590-1598, 2015

63. Liava A, Francione S, Tassi L, Lo Russo G, Cossu M, Mai R, et al. : Individually tailored extratemporal epilepsy surgery in children: anatomoelectro-clinical features and outcome predictors in a population of 53 cases. Epilepsy Behav 25 : 68-80, 2012

64. Liava A, Mai R, Tassi L, Cossu M, Sartori I, Nobili L, et al. : Paediatric epilepsy surgery in the posterior cortex: a study of 62 cases. Epileptic Disord 16 : 141-164, 2014

65. Lüders HO, Najm I, Nair D, Widdess-Walsh P, Bingman W : The epileptogenic zone: general principles. Epileptic Disord 8 Suppl 2 : S1-S9, 
2006

66. Ma BB, Rao VR : Responsive neurostimulation: candidates and considerations. Epilepsy Behav 88 : 388-395, 2018

67. Maillard LG, Tassi L, Bartolomei F, Catenoix H, Dubeau F, Szurhaj W, et al. : Stereoelectroencephalography and surgical outcome in polymicrogyria-related epilepsy: a multicentric study. Ann Neurol 82 : 781-794, 2017

68. Mathon B, Clemenceau S, Hasboun D, Habert MO, Belaid H, NguyenMichel VH, et al. : Safety profile of intracranial electrode implantation for video-EEG recordings in drug-resistant focal epilepsy. J Neurol 262 : 26992712, 2015

69. McGonigal A, Bartolomei F, Régis J, Guye M, Gavaret M, Trébuchon-Da Fonseca A, et al. : Stereoelectroencephalography in presurgical assessment of MRI-negative epilepsy. Brain 130(Pt 12) : 3169-3183, 2007

70. Minotti L, Montavont A, Scholly J, Tyvaert L, Taussig D: Indications and limits of stereoelectroencephalography (SEEG). Neurophysiol Clin 48 : 15-24, 2018

71. Moles A, Guénot M, Rheims S, Berthiller J, Catenoix H, Montavont A, et al. : SEEG-guided radiofrequency coagulation (SEEG-guided RF-TC) versus anterior temporal lobectomy (ATL) in temporal lobe epilepsy. J Neurol 265 : 1998-2004, 2018

72. Mullin JP, Sexton D, Al-Omar S, Bingaman W, Gonzalez-Martinez J : Outcomes of subdural grid electrode monitoring in the stereoelectroencephalography era. World Neurosurg 89 : 255-258, 2016

73. Mullin JP, Shriver M, Alomar S, Najm I, Bulacio J, Chauvel P, et al. : Is SEEG safe? A systematic review and meta-analysis of stereo-electroencephalography-related complications. Epilepsia 57 : 386-401, 2016

74. Munari C, Lo Russo G, Minotti L, Cardinale F, Tassi L, Kahane P, et al. : Presurgical strategies and epilepsy surgery in children: comparison of literature and personal experiences. Childs Nerv Syst 15 : 149-157, 1999

75. Neuroimaging Subcommision of the International League Against Epilepsy : Commission on diagnostic strategies: recommendations for functional neuroimaging of persons with epilepsy. Epilepsia 41 : 13501356,2000

76. Nowell M, Sparks R, Zombori G, Miserocchi A, Rodionov R, Diehl B, et al. : Comparison of computer-assisted planning and manual planning for depth electrode implantations in epilepsy. J Neurosurg 124 : 18201828, 2016

77. Onal C, Otsubo H, Araki T, Chitoku S, Ochi A, Weiss S, et al. : Complications of invasive subdural grid monitoring in children with epilepsy. J Neurosurg 98 : 1017-1026, 2003

78. Perry MS, Donahue DJ, Malik SI, Keator CG, Hernandez A, Reddy RK, et al. : Magnetic resonance imaging-guided laser interstitial thermal therapy as treatment for intractable insular epilepsy in children. J Neurosurg Pediatr 20 : 575-582, 2017

79. Pindrik J, Hoang N, Smith L, Halverson M, Wojnaroski M, McNally K, et al. : Preoperative evaluation and surgical management of infants and toddlers with drug-resistant epilepsy. Neurosurg Focus 45 : E3, 2018

80. Rahman M, Murad GJ, Mocco J : Early history of the stereotactic apparatus in neurosurgery. Neurosurg Focus 27 : E12, 2009

81. Reif PS, Strzelczyk A, Rosenow F : The history of invasive EEG evaluation in epilepsy patients. Seizure 41 : 191-195, 2016

82. Ross L, Naduvil AM, Bulacio JC, Najm IM, Gonzalez-Martinez JA : Stereoelectroencephalography-guided laser ablations in patients with neocortical pharmacoresistant focal epilepsy: concept and operative technique. Oper Neurosurg (Hagerstown) 15 : 656-663, 2018

83. Ryvlin $\mathrm{P}$, Cross $\mathrm{JH}$, Rheims $\mathrm{S}$ : Epilepsy surgery in children and adults. Lancet Neurol 13 : 1114-1126, 2014

84. Sacino MF, Huang SS, Schreiber J, Gaillard WD, Oluigbo CO : Is the use of stereotactic electroencephalography safe and effective in children? A meta-analysis of the use of stereotactic electroencephalography in comparison to subdural grids for invasive epilepsy monitoring in pediatric subjects. Neurosurgery, 2018 [Epub ahead of print]

85. Simon SL, Telfeian A, Duhaime AC : Complications of invasive monitoring used in intractable pediatric epilepsy. Pediatr Neurosurg 38 : 4752,2003

86. Tanriverdi T, Ajlan A, Poulin N, Olivier A : Morbidity in epilepsy surgery: An experience based on 2449 epilepsy surgery procedures from a single institution. J Neurosurg 110 : 1111-1123, 2009

87. Taussig D, Chipaux M, Lebas A, Fohlen M, Bulteau C, Ternier J, et al. : Stereo-electroencephalography (SEEG) in 65 children: an effective and safe diagnostic method for pre-surgical diagnosis, independent of age. Epileptic Disord 16 : 280-295, 2014

88. Taussig D, Dorfmüller G, Fohlen M, Jalin C, Bulteau C, Ferrand-Sorbets S, et al. : Invasive explorations in children younger than 3 years. Seizure $21: 631-638,2012$

89. Taussig D, Lebas A, Chipaux M, Jan M, Fohlen M, Bulteau C, et al. : Stereo-electroencephalography (SEEG) in children surgically cured of their epilepsy. Neurophysiol Clin 46 : 3-15, 2016

90. Thompson SA, Kalamangalam GP, Tandon N : Intracranial evaluation and laser ablation for epilepsy with periventricular nodular heterotopia. Seizure 41 : 211-216, 2016

91. Vadera S, Mullin J, Bulacio J, Najm I, Bingaman W, Gonzalez-Martinez $\mathrm{J}$ : Stereoelectroencephalography following subdural grid placement for difficult to localize epilepsy. Neurosurgery 72 : 723-729; discussion 729,2013

92. Vakharia VN, Sparks R, O'Keeffe AG, Rodionov R, Miserocchi A, McEvoy $A$, et al. : Accuracy of intracranial electrode placement for stereoencephalography: a systematic review and meta-analysis. Epilepsia 58 : 921-932, 2017

93. Wei PH, An Y, Fan XT, Wang YH, Yang YF, Ren LK, et al. : Stereoelectroencephalography-guided radiofrequency thermocoagulation for hypothalamic hamartomas: preliminary evidence. World Neurosurg 114 : e1073-e1078, 2018

94. Wiebe S, Blume WT, Girvin JP, Eliasziw M, Effectiveness and Efficiency of Surgery for Temporal Lobe Epilepsy Study Group : A randomized, controlled trial of surgery for temporal-lobe epilepsy. N Engl J Med 345 : 311-318, 2001

95. Wyllie E, Comair YG, Kotagal P, Bulacio J, Bingaman W, Ruggieri P : Seizure outcome after epilepsy surgery in children and adolescents. Ann Neurol 44 : 740-748, 1998

96. Yang M, Ma Y, Li W, Shi X, Hou Z, An N, et al. : A retrospective analysis 
of stereoelectroencephalography and subdural electroencephalography for preoperative evaluation of intractable epilepsy. Stereotact Funct Neurosurg 95 : 13-20, 2017

97. Yang PF, Zhang HJ, Pei JS, Tian J, Lin Q, Mei Z, et al. : Intracranial electroencephalography with subdural and/or depth electrodes in children with epilepsy: techniques, complications, and outcomes. Epilepsy Res
$108: 1662-1670,2014$

98. Youngerman BE, Oh JY, Anbarasan D, Billakota S, Casadei CH, Corrigan EK, et al. : Laser ablation is effective for temporal lobe epilepsy with and without mesial temporal sclerosis if hippocampal seizure onsets are localized by stereoelectroencephalography. Epilepsia 59 : 595-606, 2018 